\title{
Thoughts on the Development of Accounting under the Background of Informationization
}

\author{
Shui Jiang \\ Academy of Economics and Management \\ North China Electric Power University \\ Beijing, China
}

\begin{abstract}
In the present era, information technology continues to develop in-depth. Some new technologies, such as Big Data and cloud computing are emerging, constantly changing our lives. In this context, information technology has gradually penetrated the accounting field, profoundly changing the accounting industry's development process, and has brought huge challenges to accountants. This paper addresses the challenges that information technology brings to the accounting industry and gives corresponding countermeasures to promote accounting's better development.
\end{abstract}

\section{INTRODUCTION}

With the rapid development of the Internet and computer technology, and the widespread application of emerging technologies such as fifth-generation mobile communication technology, blockchain, and Big Data, the information age has arrived.

The information age emphasizes the importance of industrial technology and pays more attention to technological research and development and model innovation under information technology. Its appearance has greatly improved the efficiency of resource use and our own learning efficiency and has brought a huge impact on the development process of our society and the production and life of human beings. Similarly, with the advent of the information age, the accounting industry has also undergone tremendous changes.

\section{THE ARRIVAL OF THE INFORMATION AGE}

\subsection{The Application of Information Technology in Enterprise Production}

In today's era, the integration of enterprise production and operation activities with information technology has become closer, and the development of enterprise production is increasingly dependent on the use of information technology. Take a manufacturing company as an example. When a manufacturing company purchases raw materials, it can learn about the quality and price of raw materials in different regions and manufacturers' contact information through network information to select the highest quality raw materials.
At the same time, enterprises use information technology in the production process to monitor product status in real-time, reduce product loss, and provide a more accurate basis for enterprises to make production decisions. In addition, we can establish an employee performance evaluation database through information technology, which reduces the subjective factors in the selection of outstanding employees, promotes the openness and fairness of the employee evaluation process, which helps to stimulate employees' production enthusiasm.

\subsection{The Application of Information Technology in Education}

With the development of information technology, teachers' teaching methods, teaching models, and students' learning methods are changing. Information technology has brought more convenience to the learning process. Teachers can choose different teaching locations through the Internet, and the educated can arrange learning plans according to their own circumstances, which greatly improves the efficiency of learning and teaching. More and more schools use VR technology to help students create a vivid and realistic learning environment, which brings students an immersive learning experience, thereby improving their learning efficiency. Also, information technology has made educational resources more equitable. Whether students are in first-tier cities or poor areas, they can obtain high-quality educational resources and the information they need on the Internet. Information technology has broken the geographical restrictions of educational resources and promoted the better development of education. 


\subsection{Application of Information Technology in the Prevention and Control of the 2019 Novel Coronavirus}

In the prevention and control of the 2019 Novel Coronavirus, information technology has played a huge role. Through mobile phone communication users' relevant information, the government can keep abreast of people's life dynamics and action trajectories, solve the problems of the people in difficulties in time, and ensure people's normal food supply during the epidemic; the government can find out the travel of people infected with the epidemic through traffic big data analysis And conduct a timely investigation to determine the source of the epidemic quickly.

By counting the number of infected patients, combining the number of newly diagnosed, suspected, dead, and cured cases of the epidemic, with the help of big data and cloud computing technology, government departments can predict important information such as the peak inflection point of the epidemic. According to the predicted development trend of the epidemic, the health department can strengthen health measures in key areas, increase admission and cure rates, reduce the rate of infection and death, and avoid secondary outbreaks of the epidemic. The application of this information technology has provided important support for epidemic prevention.

\section{Challenges for accounting in the INFORMATION AGE}

\subsection{Challenges for Accounting Theory System}

Nowadays, Internet technology is widely used, which makes virtual enterprises emerge as the times require. The accounting entities of virtual enterprises are not the same as those in the traditional sense. A virtual enterprise is a temporary loose alliance that depends on the existence of the Internet. The spatial scope stipulated by the accounting entity's assumption has been broken. We can find that many virtual enterprises have emerged in addition to traditional physical companies, such as online companies and e-commerce companies. As time changes, the virtual enterprise's life span and space are constantly changing. Information technology can break through the space and time interval between companies and connect many companies. Since virtual enterprise doesn't have a fixed form and fixed time range, the accounting entity will frequently change, making the boundary of the accounting entity blurred, and the accounting period will become difficult. Besides, with the advent of the information age, accounting information provided by currency as a unit of measurement cannot meet the needs of information users. Some important corporate resources cannot be measured in currency and cannot be reflected in corporate financial statements. Besides, with the widespread application of information technology, companies face various risks every day so that the continuous operation hypothesis may be broken by bankruptcy cannot be established.

\subsection{Challenges for Accountants}

In the context of the information age, the development of information sharing and data analysis technology has improved data processing speed and the accuracy of data collection, which allows accountants to promptly discover problems in corporate management and bring great convenience to them. Moreover, the speed at which accounting information users obtain accounting information has been improved, which is conducive to information users using the information to make decisions.

But the development of information technology has also brought huge challenges to the development of accounting. In the information age, companies are increasingly using intelligent financial software, which can replace financial workers' basic accounting work. Some highly technological companies have used intelligent financial robots to efficiently operate and process the high-repetition-rate and standardized processes in the financial process. The financial robot can work continuously for 24 hours, which greatly improves accounting work efficiency and reduces the company's production costs. Besides, the continuously upgraded financial information-sharing system integrates the data of the enterprise's production and sales links, further liberating the traditional financial accounting personnel and basic management accounting personnel, and has a huge impact on the career of accounting personnel. Some junior accounting staff may face the risk of unemployment.

\subsection{Challenges for the Accounting Teaching System in University}

Nowadays, accounting courses are set from traditional accounting calculation, and there are relatively few courses on information technology. Teaching is still mainly based on an accounting calculation and accounting statement compiling. Teachers neglect the combination development of information technology and financial information in the process of teaching knowledge. Students also rarely come into contact with accounting information technology and do not understand modern enterprises' requirements for accounting talents. In such an educational environment, universities' accounting talents are often not suitable for the requirements of the information age.

\section{COUNTERMEASURES FOR THE ACCOUNTING IN THE CONTEXT OF INFORMATIONIZATION}

In recent years, with the emergence of new technologies, accounting personnel must grasp the trend of the times, conform to the current reforms, establish a lifelong learning concept, and continuously improve their professional quality. 


\subsection{Accountant Must Change Their Way of thinking and Participate in Company Management Decisions}

Most accounting practitioners will have this idea: As long as I do a good job of my usual account and reimburse the enterprise's daily expenses, this is a good accountant. But in fact, accountants can't limit their thinking to income accounting and the figures in financial statements. With the advent of the information age, accounting practitioners must understand the company from the viewpoint of further perfection and understand the company's production process, product pricing, and sales. For this reason, the accounting personnel should expand their knowledge fields to understand the knowledge of budget, cost management, e-commerce, and other fields, to better participate in the business decision-making of the enterprise.

\subsection{Enterprises Should Develop Financial Information Technology}

Facing the advent of the information age, some small and medium-sized enterprises often do not pay attention to financial information construction. The security of corporate financial information needs to be improved. With the development of Internet technology and data analysis technology, in the management and construction of accounting information for enterprises, information technology for accounting information management has gradually become the trend of social development. Enterprises adopting information technology to manage accounting information can improve their production efficiency, reduce their operating costs, and meet the company's sustainable development's fundamental needs. However, in reality, some business managers do not fully understand the role of informatization in accounting, limiting enterprises' development to a certain extent, and reducing their competitiveness. Besides, the accounting information analysis technology of many small and medium-sized enterprises lags. Accounting information software still has many shortcomings in its application performance. The application is relatively poor and cannot fully meet the requirements of enterprises for accounting information management. It does not give full play to accounting information software in the company-role in decision-making. Due to the above reasons, the existing accounting information software and information analysis technology cannot be popularized and operated in small and medium-sized enterprises.

Therefore, business managers must fully understand the application of information technology in accounting to help enterprises carry out accounting work effectively. At the same time, after introducing advanced information processing technology, organize accounting workers to conduct exchanges and training to truly enable accounting personnel to work the application of information technology. Accounting personnel must also follow the development trend of this era, establish crisis awareness, and learn the corresponding computer application technology. Accounting practitioners should understand and master the operation of financial systems and software, be familiar with the operation process of information software, precautions, and functions that can be realized, and strive to learn the relevant knowledge of operating software. Accountants should combine their own work content with information technology in their actual work, improve their ability to integrate enterprise operating data, enhance their own business standards, and improve their own competitiveness.

\subsection{Develop and Improve Accounting Theory}

With the continuous emergence of new business forms, traditional accounting assumptions may not be suitable for the accounting work of such enterprises. Accounting entity hypothesis, accounting installment hypothesis, continuous operation hypothesis, and monetary measurement hypothesis have received a huge impact. Therefore, it is necessary to adapt to the information age and the development of new enterprises, expand the connotation and extension of the accounting theory system, and make it more suitable for the development needs of the times.

\subsection{Accounting Education Should be Integrated with Information Technology}

First of all, universities must innovate in accounting teaching methods. Colleges and universities can use the rich educational resources and different teaching methods on the Internet to improve teachers' teaching efficiency and enhance students' autonomous learning ability. Secondly, universities should change their thinking of cultivating accounting talents and promoting a new accounting discipline system. It is necessary to strengthen the curriculum reform and add courses related to information technology such as computers and management software. Finally, universities should strengthen the construction of accounting teachers. In the teaching process, teachers should pay more attention to accounting management functions, rather than teaching simple accounting work. The implementation of these measures can make the accounting talents cultivated by universities more suitable for developing the information age.

\section{Conclusion}

The advent of the information age has brought earthshaking changes to our lives and all walks of life. It makes information acquisition more convenient, greatly improves resource integration efficiency, and profoundly changes the development direction of human society. Simultaneously, the information age has also brought a huge impact on the development of the accounting industry. Information technology has made accounting information processing more intelligent and efficient. Some tedious accounting tasks are replaced by intelligent software, and some accountants may be replaced. Traditional accounting teaching courses and accounting talents are no longer suitable for the requirements of the current era. 
Therefore, accounting practitioners actively change their own development methods, conform to the development trend of the times, combine professional knowledge with information technology, and participate in the company's business decision-making to not be eliminated by the times. Companies must follow the trends of the times, accelerate the application of accounting information technology, enhance the company's market competitiveness, and improve its financial governance environment. Accounting teaching in colleges and universities should be reformed and innovated to cultivate talents that meet the development needs of society's times. Only when the accounting industry reforms itself following the development trend can it have a better future and make greater contributions to economic and social development.

\section{ACKNOWLEDGMENT}

After a long and arduous process, the paper was finally completed. In this process, I cannot finish it without the support and encouragement of teachers, family members, and classmates. First of all, I would like to express my sincere gratitude to teachers who have taught me. The knowledge they taught gave me a lot of inspiration. Their rigorous spirit in pursuing academics and their enthusiasm for work deeply infected me. My English accounting teacher, Ms. Guo, gave me a lot of guidance and support during the writing process and gave me the courage to continue writing. I sincerely thank the teachers for their selfless help. They are the beacon on my way forward. Also, I want to extend my gratitude to my family and classmates for encouraging me when I encounter difficulties so that I can persevere. Finally, I once again express my sincere gratitude to the teachers, family, and classmates who helped and supported me.

\section{REFERENCES}

1. Shu Huifang. The Background of the Internet to Research the Reform of Teaching Mode of Accounting Course under. 2020, 3(6)

2. Bei Chen. Research and Practice on the Training of International Applied Accounting Professionals. 2020, 2(3)

3. Shengzhu Li, Wei Tan. The Coping Strategies of Accountants Under the Background of Artificial Intelligence. 2020, 3(7)

4. Yiying Huang Challenges and countermeasures of management accounting in the era of big data[J]. China Market, 2020(01):195-196.

5. Zafeer Nagdee. Accounting bases of theory: Why they matter. 2016, 6(4 (Continued-1))

6. Chaohui Zhang. Opportunities and Challenges Faced by Accounting Theory in the Era of "Internet +" Big Data[J]. Accounting Learning, 2020(18): 114-115. (in Chinese)

7. Xinli Yuan, Qi Zhang. Big Data provides "Smart Support" for epidemic prevention and control[J]. China Telecommunications Trade, 2020(02):16-17. (in Chinese)

8. Zhang Chaohui. Opportunities and challenges faced by accounting theory in the era of "Internet + " Big Data[J]. Accounting Study, 2020(18): 114-115.(in Chinese) 